\section{Intersimple Sequence Repeat Fingerprinting and Genetic Variation in a Collection of Clematis Cultivars and Commercial Germplasm}

\author{
Nicole Gardner ${ }^{1}$ and Stan C. Hokanson ${ }^{2}$ \\ Department of Horticultural Science, University of Minnesota, St. Paul, \\ MN 55108
}

Additional index words. ISSR

\begin{abstract}
The genus Clematis contains many well-known large flowered cultivars, as well as lesser-known nonvining species. Intersimple sequence repeat (ISSR) primers were used to fingerprint 32 vining cultivars and five nonvining species $(C$. fruiticosa, $C$. integrifolia, $C$. heracleifolia, $C$. hexapetala, and $C$. recta) for use in assessing genetic relationships and cultivar identification. Four ISSR primers yielded a total of 44 bands in the vining accessions, of which $36(86 \%)$ were polymorphic. The average polymorphism levels were $83 \%$ for the cultivars and $94 \%$ for the nonvining species. All 32 vining cultivars were distinguished with the use of two ISSR primers, and the five nonvining Clematis species were differentiated with three ISSR primers. A similarity matrix of the cultivars showed low similarity levels between the samples, with an average similarity of 0.28. A UPGMA-derived dendrogram showed no strong groupings among any of the samples. Two cultivars with known parentage, Clematis viticella L. 'Betty Corning' and 'Sylvia Denny', grouped with one reported parent but not the other, suggesting they are more similar to one parent. 'Multi-blue', a sport reportedly arising from 'The President' did not segregate near 'The President'.
\end{abstract}

The genus Clematis contains more than 100 species making up a diverse mix of plant and flower forms, sizes, and colors. Plants in this genus are mainly woody and most species are vining climbers. Flowering vining species, such as $C$. terniflora and $C$. viticella, have been cultivated since the end of the 16th century (Fisk, 1994). Although several of these vining species are sold as cultivars, the most popular Clematis are large flowered hybrids made from crosses between several different species, some of which were introduced more than 100 years ago. (Fair and Fair, 1990). Sales of large flowering cultivars today are strong. Annual sales for climbing Clematis in the U.S. were \$14 million in 1998, making up more than a third of the total number of vines sold in the U.S. (USDA-NASS, 1998).

Although Clematis is best known for vining species and cultivars, there are several nonvining species (Fisk, 1994). Many of these are shrubby, either herbaceous or woody, and several of these species are already cultivated for ornamental use, although not widely planted (Evinson, 1998). The nonvining species have

Received for publication 9 May 2005. Accepted for publication 28 July 2005. Journal series paper 041210132 of the Department of Horticultural Science. This research was paid for in whole, or in part, by the Minnesota Agricultural Experiment Station. We thank Harold Pellett for supplying plant material and reviewing the manuscript, and Steve McNamara and Kathy Zuzek for assistance in conducting the research.

${ }^{1}$ Former graduate student, Currently research fellow, University of Minnesota, Dept. of Horticultural Science.

${ }^{2}$ Assistant professor, Corresponding author; e-mail hokan017@umn.edu. a wider variety of leaf and flower shapes than most commonly sold vining species, which adds to their value.

Molecular markers have been used increasingly in the breeding programs of many horticultural crops. Molecular markers can pro-

Table 1. Vining Clematis cultivars and accessions, source of plant material, and parentage of known cultivars. $\mathrm{BB}=$ Bluebird Nurseries, MLA $=$ Minnesota Landscape Arboretum .

\begin{tabular}{lcl}
\hline Accession Name & Source & Parentage (if known) \\
\hline 'Asao' & BB & \\
'Bees Jubilee' & BB & \\
'Duchess of Edinburgh' & BB & \\
'General Sikorski' & BB & \\
'Gipsy Queen' & BB & \\
'Hagley's Hybrid' & MLA & C. integrifolia 'Rosea' × 'Warsaw Nike' \\
'Henryi' & BB & \\
'Inspiration' & MLA & \\
'Jackmanii' & MLA & \\
'Madame de Bouchaud' & BB & \\
'Marie Boisselet' & BB & \\
'Miss Bateman' & BB & \\
'Multi Blue' & MLA & \\
'Nelly Moser' & BB & \\
'Not Nelly Moser" & BB & \\
'Niobe' & BB & \\
'Pink Champagne' President' \\
'Prince Charles' & BB & \\
'Rouge Cardinal' & BB & \\
'Royalty' & BB & \\
'Sylvia Denny' & BB & \\
'The President' & MLA & \\
'Warsaw Nike' & MLA & \\
C. $\times$ huldine & MLA & \\
C. crispa & MLA & \\
C. integrifolia 'Rosea' & MLA & \\
C. integrefolia 'Durandii' & BB & \\
C. macropetala 'Markham's Pink' & MLA & \\
C. viticella & MLA & \\
C. vitricella 'Betty Corning' & MLA & \\
C. vitricella 'Polish Spirit' & MLA & \\
C. terniflora (paniculata) & BB & \\
& MLA &
\end{tabular}

vide valuable information about germplasm. Unique fingerprints determined with markers can be used in protecting proprietary rights (Congiu et al., 2000), or ensuring that plant material is correctly labeled (Keil and Griffin, 1994). The degree of similarity between the banding patterns can provide information about genetic similarity, and relationships between the samples studied can be revealed by dendrograms based on the similarity data. Such information has not previously been available for the Clematis genus. The objectives of this study were, therefore, to develop unique genetic fingerprints for a collection of the more popular vining Clematis cultivars with ISSRs, and to estimate genetic diversity and relatedness between Clematis cultivars and species.

Several molecular marker systems are now available for use on plant species. Each marker system has its own strengths and limitations, making the choice of marker an important decision. Intersimple sequence repeat markers (ISSRs) (Zietkiewicz et al., 1994) have been used successfully on a number of horticultural species including mulberry (Morus spp.) (Vijayan and Chatterjee, 2003); strawberry (Fragaria ananassa L.,) (Arnau et al., 2002); chestnut (Castanea sative Mill.) (Casasoli et al., 2001) cashew (Anacardium occidentale L.) (Archak et al., 2003) and potato (Solanum tuberosum L.) (Prevost and Wilkinson, 1999). The markers have proven to be more reproducible than randomly amplified polymorphic DNA (RAPD) markers (Yang et al., 1996; Nagaoka and Ogihara, 1997) and generally reveal higher levels of polymorphism (Casasoli et al., 2001; Nagoaka and Ogihara, . 
1997, Yang et al., 1996). They cost less and are easier to use than amplified fragment-length polymorphisms (AFLPs) and do not require prior knowledge of flanking sequences like simple sequence repeats (SSRs) (Reddy et al., 2002). Due to these advantages over the other commonly used marker systems, ISSRs were chosen for use in this study.

\section{Materials and Methods}

Plant material. Five nonvining speciesClematis hexapetala, C. recta, C. heracleifolia, C. integrifolia, and C. fruiticosa - and $32 \mathrm{com}$ monly available vining cultivars and species (referred to in this paper as vining cultivars) (Table 1) were examined in this study. Six individuals were genotyped for each of the nonvining species. Clematis recta, $C$. heracleifolia, C. integrifolia, C. fruiticosa plants and a number of the vining cultivars were obtained from Bluebird Wholesale Nursery, Clarkson, Neb. Clematis hexapetala plants were collected in the Russian far east $43^{\circ} 58^{\prime} 7.5^{\prime \prime} \mathrm{N}$ and $131^{\circ}$ $25^{\prime} 57.8^{\prime \prime} \mathrm{E}$ at an elevation of about 500 feet. The remaining vining cultivars were collected from plantings at the Minnesota Landscape Arboretum (MLA), Chanhassen. Two of the original 'Nelly Moser' plants purchased from Bluebird Nursery had flower morphology completely different from the 'Nelly Moser' cultivar descriptions. These plants were kept in the study under the name "Not Nelly Moser". Two more plants were purchased from Bluebird Nursery that looked true to type. Both true and off-type 'Nelly Moser' were genotyped in an attempt to determine their true identities.

DNA extraction. Leaf tissue used for DNA extraction was collected from actively growing shoots, immediately placed on ice and then frozen at $-80{ }^{\circ} \mathrm{C}$ until extraction. DNA was extracted according to Haymes (1996) with the following modifications: $500 \mu$ Lextraction buffer was added to the leaf tissue and incubated $15 \mathrm{~min}$. The amount of chloroform-isomyl alcohol was increased to $500 \mu \mathrm{L}$ and an additional $200 \mu \mathrm{L}$ chloroform-isomyl alcohol step was added for further purification of the DNA. After drying, the samples were resuspended in $200 \mu \mathrm{L}$ cell culture water (Celox Laboratories Inc., Saint Paul, Minn.) and quantified using a spectrophotometer. Each sample was diluted to a concentration of $25 \mathrm{ng} \cdot \mu \mathrm{L}^{-1}$ and stored at $-20{ }^{\circ} \mathrm{C}$.

To determine the reproducibility of banding patterns across separate extractions, replicate DNA extractions were performed for the sixteen vining cultivars from Bluebird Nurseries on a set of leaves taken from separate clonal plants. Each pair of extractions was amplified and run side by side in each gel so that banding patterns could be easily compared. The set of replicate extractions was amplified three times for comparison of banding patterns in separate amplifications

ISSR primers. Nine ISSR primers were synthesized by Integrated DNA Technologies (Coralville, Iowa) for use in this study. Initial primer selections were based on University of British Columbia (UBC) primers commonly found in plant literature. All of the primers used in this study contained dinucleotide repeats (Table 2). Six of the primers were anchored at the $3^{\prime}$ end and three were anchored at the $5^{\prime}$ end.

DNA amplification. DNA amplifications were performed in a $25 \mu \mathrm{L}$ volume containing $10 \times$ PCR buffer, $2.5 \mathrm{~mm}$ dNTP mix, $1.0 \mathrm{~mm}$ $\mathrm{MgCl}_{2}$ (all supplied with the enzyme), $20 \mu \mathrm{M}$ primer, 0.625 units Taq (TaKaRa, Otsu, Shiga, Japan), 2\% formamide, distilled filtered water, and $25 \mathrm{ng}$ genomic DNA. Samples were run in a GeneAmp 2700 thermal cycler (Applied Biosystems, Foster City, Calif.) programmed with a 7-min denaturation at $94{ }^{\circ} \mathrm{C}$ followed by 50 cycles of $94{ }^{\circ} \mathrm{C}$ for $45 \mathrm{~s}, 52{ }^{\circ} \mathrm{C}$ for 45 $\mathrm{s}$, and $72{ }^{\circ} \mathrm{C}$ for $2 \mathrm{~min}$, with a final 7 -min extension at $72{ }^{\circ} \mathrm{C}$.

Electrophoresis. A $14.5-\mu \mathrm{L}$ aliquot of each reaction was run on a $2 \%$ agarose gel in $1 \times$ TAE buffer, with $5 \mu \mathrm{g} \cdot \mathrm{mL}^{-1}$ ethidium bromide in both the buffer and gel. The gels were visualized and photographed under UV light using an Alpha Innotech digital camera (Alpha Innotech Corp., San Leandro, Calif.). Molecular weights were estimated in comparison to a 1 $\mathrm{kb}$ ladder (Invitrogen, Carlsbad, Calif.). At least three amplifications were run for each of the cultivars studied, and a minimum of four amplifications were run for the species samples studied to ensure repeatability of the banding patterns.

Data analysis. Digital photographs of each gel were imported into Photoshop 6.0 (Adobe, San Jose, Calif.). Images were scored visually, with bands recorded as either present (1) or absent $(0)$. Bands considered present appeared in at least two of three or three of four amplifications for cultivars and species, respectively.

Table 2. Sequences and banding information for primers used in this study. $B=C / G / T ; D=A / G / T ; H=$ $\mathrm{A} / \mathrm{C} / \mathrm{T} ; \mathrm{R}=\mathrm{A} / \mathrm{G} \mathrm{V}=\mathrm{A} / \mathrm{C} / \mathrm{G} ; \mathrm{Y}=\mathrm{C} / \mathrm{T}$.

\begin{tabular}{|c|c|c|c|}
\hline Primer & $\begin{array}{c}\text { Repeat } \\
\text { sequence } \\
5^{\prime}-3^{\prime}\end{array}$ & $\begin{array}{r}\text { Total } \\
\text { bands }\end{array}$ & $\begin{array}{c}\text { Polymorphic } \\
\text { bands }\end{array}$ \\
\hline$\overline{\mathrm{UBC}} 811$ & (GA)8C & Inconsistent & \\
\hline UBC818 & (CA) $8 \mathrm{G}$ & 19 & 18 \\
\hline UBC825 & $(\mathrm{AC}) 8 \mathrm{~T}$ & 20 & 19 \\
\hline UBC841 & (GA)8YC & 20 & 17 \\
\hline UBC848 & (CA)8RG & 17 & 11 \\
\hline UBC849 & (GT)8YA & Smeared & \\
\hline UBC888 & $\mathrm{BDB}(\mathrm{CA}) 7$ & Smeared & \\
\hline UBC890 & VHV(GT)7 & Smeared & \\
\hline UBC891 & HVH(TG)7 & Smeared & \\
\hline
\end{tabular}

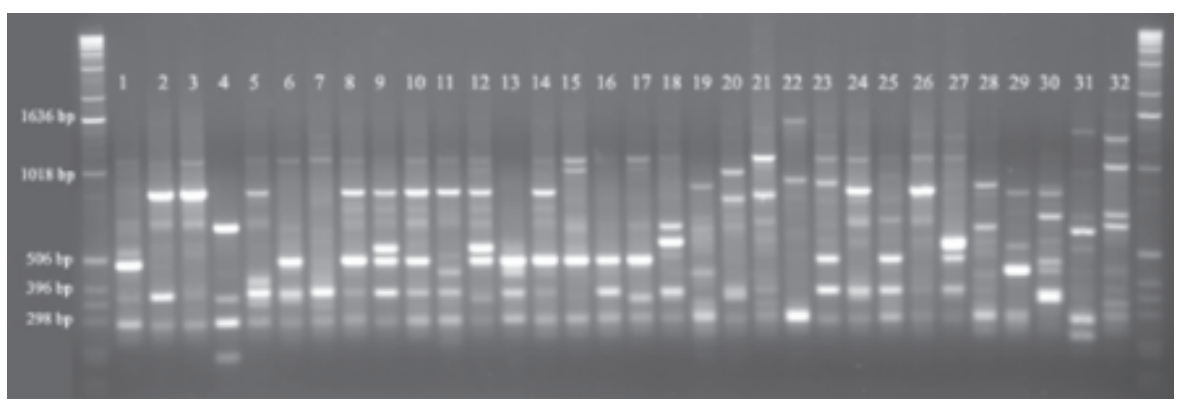

Fig. 1. Digital photograph of $2 \%$ agarose gel of vining cultivars amplified with primer UBC841. Lanes (from left to right): 1-kb marker, 1 = 'Pink Champagne', 2 = 'Rouge Cardinal', $3=$ 'Niobe', 4 = 'Madame de Bouchaud', 5 = 'Hagley's Hybrid', 6 = 'Marie Boisselet', 7 = 'Miss Bateman', 8 = 'Prince Charles', 9 $=$ 'Royalty', $10=$ 'Henryi', $11=$ 'Bees Jubilee', 12 = 'General Sikorski', 13 = "Not Nelly Moser", 14 = 'Asao', $15=$ 'Jackmanii', 16 = 'The President', $17=$ 'Durandii', $18=$ 'Polish Spirit', $19=$ 'Gipsy Queen', 20 = 'Huldine', 21 = 'Inspiration', $22=$ C. crispa, 23 = 'Duchess of Edinburgh', $24=$ 'Sylvia Denny', 25 = 'Multi Blue', 26 = 'Warsaw Nike', 27 = 'Nelly Moser', $28=$ C. viticella, $29=$ 'Betty Corning', $30=$ C. terniflora, 31 = 'Markham's Pink', $32=$ C. integrifolia 'Rosea'. 
Table 3. Percent of polymorphic and unique bands uncovered with each primer for the nonvining Clematis species and vining cultivars.

\begin{tabular}{llllll}
\hline & \multicolumn{2}{c}{ Polymorphic markers (\%) } & & \multicolumn{2}{c}{ Unique markers (\%) } \\
\cline { 2 - 3 } Primer & \multicolumn{1}{c}{ Species } & \multicolumn{1}{c}{ Cultivars } & & Species & Cultivars \\
\hline UBC 818 & $100.0(11 / 11)$ & $88.8(8 / 9)$ & & $63.6(7 / 11)$ & $11.1(1 / 9)$ \\
UBC 825 & $100.0(12 / 12)$ & $100.0(10 / 10)$ & & $41.6(5 / 12)$ & $0.0(0 / 10)$ \\
UBC 841 & $100.0(9 / 9)$ & $76.9(10 / 13)$ & & $44.4(4 / 9)$ & $23.1(3 / 13)$ \\
UBC 848 & $90.9(10 / 11)$ & $66.6(8 / 12)$ & & $50.0(6 / 12)$ & $33.3(4 / 12)$ \\
Average & 97.5 & 83.1 & & 49.9 & 16.9 \\
\hline
\end{tabular}

of the vining cultivars, band reproducibility was high. All strong bands amplified from one extraction were amplified in the replicate extraction. Only faint ghost bands were not repeatable between both extractions of the same cultivar.

The four primers used (UBC818, UBC825, UBC841, and UBC848) amplified a total of 76 scorable fragments for all the species and cultivars being investigated, giving an average of 19 fragments per primer(Table 2). Fragment size ranged from about 250 to $1400 \mathrm{bp}$ (Fig. 1). Of the 76 bands scored, 38 were found only in the vining cultivars, and 27 were unique to the nonvining species used in this study. Only 11 bands were found in both nonvining species and vining cultivars and, of these 11,7 were revealed with primer UBC 848.

The percentage of bands that were polymorphic among the genotypes sampled varied by primer. In general, polymorphism levels were high. Primers UBC818 and UBC825 had the highest percentage of polymorphic bands $(95 \%)$ and UBC 848 had the lowest percentage (65\%; Table 2). The primers also varied in the number of unique bands that each produced. Primer UBC818 produced the highest percentage of unique markers among samples from the nonvining species, however the percentage of unique markers in vining cultivar samples was relatively low for UBC818 (Table 3). Primer UBC848 produced the least polymorphisms of any primer in both the nonvining species and vining cultivars ( $91 \%$ and $67 \%$, respectively), however this primer did produce a relatively high number of unique bands in both species and cultivar samples (50\% for nonvining species and 33\% for vining cultivars).

Vining cultivars. In total, 44 fragments were scored for the vining cultivars, of which 36 were polymorphic $(82 \%)$. Polymorphism levels varied by primer. Markers produced by primer UBC 825 were $100 \%$ polymorphic, while those from primers UBC818, UBC841 and UBC 848 showed $89 \%, 77 \%$, and $67 \%$ polymorphism respectively (Table 3 ). All cultivars studied could be distinguished with the combined use of primers UBC 841 and UBC825.

The cultivars and nonvining species separated into two separate clusters in a dendrogram based on similarity values, however, within the cultivars the clusters were not distinct (Fig. 2). Over half of the nodes separating the cultivar samples were at similarity coefficient levels below 0.50. 'Markham's Pink', C. integrifolia 'Rosea' and C. terniflora showed the least similarity with other vining cultivars and nonvining species. The highest similarities were found between 'Niobe' and 'Madame de Bouchaud' (0.83) and the off-type 'Nelly Moser' and 'General Sikorski' (0.82).

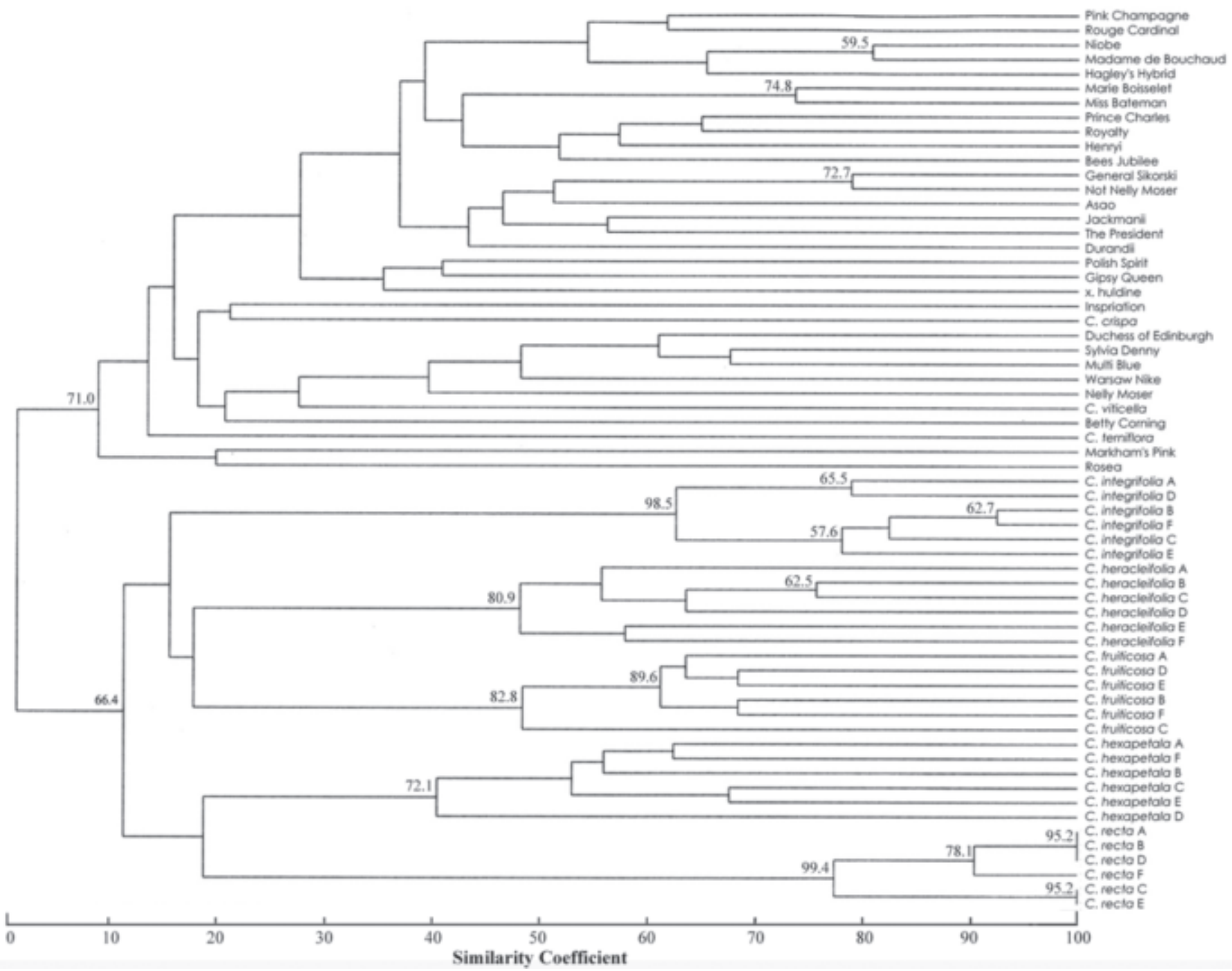

Fig. 2. Dendrogram of vining cultivars and nonvining species derived from Jaccard similarity values using UPGMA. Genotypes within the same nonvining species are distinguished by different letters after the species name. Values to the left of the node represent bootstrap values. Bootstrap values below $50 \%$ are not reported. 
Table 4. Average genetic similarity between and within nonvining Clematis species genotypes, based on Jaccard similarity coefficient comparisons. Values are the average of similarity coefficients between individual accessions. First values in each column represent the average similarity of the accessions within each species.

\begin{tabular}{lccccc}
\hline Species & C. integrifolia & C. hexapetala & C. heracleifolia & C. fruiticosa & C. recta \\
\hline C. integrifolia & 0.73 & & & & \\
C. hexapetala & 0.19 & 0.52 & & & \\
C. heracleifolia & 0.18 & 0.18 & 0.52 & 0.60 & 0.83 \\
C. fruiticosa & 0.21 & 0.14 & 0.22 & 0.12 & \\
C. recta & 0.14 & 0.23 & 0.17 & \\
\hline
\end{tabular}

In general, the cultivars with known parentage (Table 1) did not exhibit strong similarities to either of the recorded parents. Clematis viticella 'Betty Corning' did cluster with $C$. viticella, a reported parent, but the similarity level between the two genotypes was less than $30 \%$. 'Sylvia Denny', the reported progeny of a cross between 'Duchess of Edinburgh' and 'Marie Boisselet' showed more similarity to the maternal parent. 'Multi-Blue' a cultivar reported to be a sport of 'The President', had a coefficient of similarity value with 'The President' of $38 \%$.

The correlation between cophenetic values derived from the dendrogram and similarity levels was $r=0.93$, indicating that the dendrogram accurately represents the similarity data. Confidence levels obtained for the cultivar portion of the dendrogram were generally quite low (Fig. 2), with only three nodes having bootstrap values $>50 \%$.

Nonvining species. All five nonvining species were distinguished by the use of primer UBC818, UBC825, or UBC841 alone. Using primer UBC848 alone was not sufficient to distinguish among the nonvining species.

The number of polymorphic bands varied by species and primer (Table 3). All of the bands produced by primers UBC818, UBC825, and UBC841, and $91 \%$ of bands produced by primer UBC 848 were polymorphic across all the species. Clematis fruiticosa had the most polymorphic bands $(83 \%)$, as compared to $C$. recta, which had the lowest percentage of polymorphic bands (38\%) (not shown).

Clematis recta had the highest similarity levels, with the average level of similarity among the six plants at $83 \%$ (Table 4$)$. The $C$. integrifolia genotypes also had a high average similarity (73\%). The other species had average intraspecific similarities ranging from $52 \%$ to $60 \%$. Interspecific similarity levels were generally low. The greatest similarity between any two of the nonvining species was between $C$. hexapetala and $C$. recta, which had an average similarity value of 0.23 .

The UPGMA-derived dendrogram shows the five species separating into distinct clusters (Fig. 2). Bootstrap confidence levels at nodes separating the five species groups ranged from $72 \%$ to $99 \%$. Two sets of $C$. recta genotypes (C. recta $\mathrm{A}, \mathrm{B}$, and $\mathrm{D}$, and $C$. recta $\mathrm{C}$ and E) had similarity coefficients of $100 \%$ and were indistinguishable morphologically or by banding patterns (Fig. 2). Groupings within the species clusters generally were more substantiated than groupings among vining cultivars, yet most confidence levels were $<50 \%$.

\section{Discussion}

ISSR primers. Over half of the ISSR primers we tested gave clear bands, similar to results reported for ISSR primers in other plant groups (Casasoli et al., 2001; Joshi et al., 2000; Tikunov et al., 2003). All primers producing good banding patterns were anchored at the $3^{\prime}$ end, whereas primers anchored at the $5^{\prime}$ end gave smeary patterns. This effect, attributed to stuttering caused by primer annealing at different points in the simple sequence repeat, has been reported previously (Arcade et al., 2000; Ammiraju et al., 2001) although some studies have used $5^{\prime}$ anchored primers successfully (Blair et al., 1999; Reddy et al., 2002).

The percentage of polymorphic and unique markers differed across the nonvining species and the vining cultivars (Table 3 ). The nonvining species were more polymorphic for all primers studied, and also had a higher percentage of unique bands. This result agrees with studies in other genera that have found that polymorphism levels are often lower in domesticated crops as compared to related species (Virchow, 2003).

The mid-70\% reproducibility levels reported here are slightly lower than the mid-80 percent levels reported for ISSRs on agarose gels in other genera (McGregor et al., 2000; Moreno et al., 1998) but higher than some reported reproducibility levels for RAPD markers (Schnell et al., 1995). Duplicate extractions of the 16 vining cultivars that were run side by side had only faint bands that were not reproducible between the two lanes, indicating that the banding patterns were stable across extractions. The average number of bands per primer is comparable to levels in a few studies [19.6 bands in Pandorea sp. (Jain et al, 1999), 14.4 bands in Psammochloa villosa Bor. (Li and $\mathrm{Ge}, 2001)]$, but higher than results on other plant species such as Nothofagus sp., with 10.5 bands, (Mattioni et al., 2002); Humulus lupulus L., with 12.9 bands (Patzak, 2001); and Castanea sativa Mill. with 2.8 bands (Casasoli et al., 2001).

Vining cultivars. The ability of ISSR primers to distinguish between cultivars in the same species has been demonstrated previously (Charters et al., 1996; Patzak, 2001; Prevost and Wilkinson, 1999; Fang and Roose, 1997). Using ISSR primers provides an easy and effective way to fingerprint and distinguish between closely related plants.

Due to the long history of cultivation, breeding, and selection for large flowered vining Clematis, the parentage of most of the cultivars studied is unknown, making interpretation of cultivar groupings depicted in the UPGMA-generated dendrogram difficult. Clematis cultivars are often grouped according to pruning treatment and growth form, which often corresponds to parentage (Fair and Fair, 1990; Snoeijer, 1991). An attempt to correlate these pruning groups with the groupings determined in the dendrogram was unsuccessful. For example members of one of the groups, Lanuginosa ('General Sikorski', 'Henryi', and 'Nelly Moser') appear in different clusters in this study and have similarity levels of $\leq 50 \%$.

Other studies have attempted to correlate molecular marker data with known pedigrees (Oraguzie et al., 2001). Some studies using ISSRs have found that cultivar groups revealed in dendrograms agree with known pedigrees or dendrograms created with information from other marker systems (Arnau et al., 2002; Fernández et al., 2002; Tikunov et al., 2003). However, other molecular marker results can disagree with known or reported information (Archak et al., 2003; Oraguzie et al., 2001). Thus, one cannot make broad assumptions about the parentage or pedigree of cultivars used in this study based on the dendrogram. Also, the low similarity levels and bootstrap confidence levels reported here mean that most of the relationships in the dendrogram could be artificial, making a correlation with known pedigrees even less feasible.

The few cultivars with known parentage that were included in this study, such as 'Multi Blue' which is thought to be a sport of 'The President', and 'Inspiration', known to be a cross between ' $C$. integrifolia 'Rosea' and 'Warsaw Nike', did not show high similarities with reported parents (Fig. 2). Other studies have reported similar results, with this lack of congruity being attributed to faulty pedigree information (Archak et al., 2003), incomplete coverage of the genome (Denagi et al., 2001), or insufficient number of fragments scored in the analysis (Oraguzie et al., 2001).

Two cultivars, 'Betty Corning' and 'Sylvia Denny', did cluster near one of the reported parents, C. viticella and 'Duchess of Edinburgh' respectively, but not the other reported parent. Since both 'Betty Corning' and 'Sylvia Denny' clustered nearer to the paternal parent than the maternal parent, this result is not likely to be due to an error in record keeping or accidental pollination. Hybrid progeny in other species have also been shown to have more bands in common with one parent than another (Reed et al., 2002).

The low similarity level between 'The President' and its sport 'Multi-Blue' (Fig. 2) is unexpected. Generally sports are difficult to distinguish from the original clone at the molecular level, and even when differences are found, the two genotypes have high similarity values (Patzak, 2001; Starman et al., 1999; Trigiano et al., 1998). Previous reports have shown the difficulty of distinguishing between sports and original clones using ISSRs (Fang and Roose, 1997; Patzak, 2001). The dissimilarity found between 'The President' and 'Multi-Blue' suggests 'Multi-Blue is not a sport. While it is possible that the 'Multi-Blue' plants used in this study could be off-type, phenotypically 
they closely resembled photographs of a true 'Multi-Blue'.

The dissimilarity between banding patterns of 'Nelly Moser' and "Not Nelly Moser" (only $13 \%$ of bands in common), reinforces morphological data suggesting the two are not the same cultivar. The genotypic similarity between "Not Nelly Moser" and 'General Sikorski' was reinforced by morphological similarities between these two plants; both plants have similar leaf and flower shapes and both had the same light blue flower color. The fact that there were differences in banding patterns between the two genotypes suggests that "Not Nelly Moser" could be a seedling of 'General Sikorski' and not a clone or sport.

Nonvining species. ISSRs have been used to discriminate between species in many different genera including grasses (Lolium and Festuca) (Pasakinskiene et al., 2000), hop (Vigna)(Ajibade etal., 2000), tomato (Lycopersicon) (Tikunov et al., 2003), chickpea (Cicer) (Rajesh et al., 2002), and rice (Oryza) (Joshi et al., 2000). In this study of Clematis, four of the five primers used were able to distinguish among all five species.

A dendrogram of the species shows intraspecific variation among the genotypes selected for study (Fig. 2). Although the species grouped separately from each other with significant bootstrap values, there was significant within species variation. This variation agrees with information concerning propagation. All of the species purchased from Bluebird nursery were propagated by seed from a varying number of seed parents. All parent plants used to provide seed at the nursery are grown outside, but in locations well separated from each other to prevent cross-pollination. Clematis integrifolia and $C$. heracleifolia plants are propagated from five and three parents respectively. Fifteen to twenty plants selected from the seed of one accession collected by Bluebird nursery provides the seed for $C$. fruiticosa plants sold. One $C$. recta plant is the seed source for all $C$. recta plants sold by the nursery, which would explain the higher levels of similarity among C. recta as opposed to the other species studied. The greatest variation was present among $C$. hexapetala genotypes. Since these accessions were collected from naturally occurring wild populations, higher levels of genetic diversity would be expected.

This is the first known report on the use of molecular markers for creating genetic fingerprints and determining genetic relationships in Clematis species or cultivars. ISSR markers have been used successfully to reveal information about the genus in several areas. Molecular markers were useful for unequivocally differentiating a group of 32 vining cultivars using a minimum of two primers. The primers proved useful for identifying a cultivar that had been erroneously sold as 'Nelly Moser'. Five nonvining Clematis species were uniquely identified with only a single primer.

The genetic relationships suggested by a UPGMA-derived dendrogram based on genetic similarities from banding data of these species and cultivars did not always reflect known pedigree information. Progeny with known parents often did not cluster near one or either of the reported parents. Other relationships, such as the possible parentage of "Not Nelly Moser", are suggested by clustering in the dendrogram.

This study demonstrates a practical application of molecular markers for ornamental plant breeding. Often ornamental breeders work with more than a single crop, and cannot devote resources to developing molecular techniques such as SSRs for a single species. ISSR markers were developed quickly and proved to be a robust system for genetic fingerprinting in the genus.

\section{Literature Cited}

Ajibade, S.R., N.F. Weeden, and S.M. Chite. 2000. Inter simple sequence repeat analysis of genetic relationships in the genus Vigna. Euphytica 111:47-55.

Ammiraju, J.S.S., B.B. Dholakia, D.K. Santra, H. Singh, M.D. Lagu, S.A. Tamhankar, H.S. Dhaliwal, V.S. Rao, V.S. Gupta, and. P.K. Ranjekar. 2001. Identification of inter simple sequence repeat (ISSR) markers associated with seed size in wheat. Theor. Appl. Genet. 102:726-732.

Arcade, A., F. Anselin, P. Faivre Rampant, M.C. Lesage, L.E. Pâques, and D. Prat. 2000. Application of AFLP, RAPD and ISSR Markers to Genetic Mapping of European and Japanese Larch. Theor. Appl. Genet. 100:299-307.

Archak, S., A.B. Gaikwad, D. Gautam, E.V.V.B. Rao, K.R.M. Swamy, and J.L. Karihaloo. 2003. DNA fingerprinting of Indian cashew (Anacardium occidentale L.) varieties using RAPD and ISSR techniques. Euphytica 130:397-404.

Arnau, G., J. Lallemand, and M. Bourgoin. 2002. Fast and reliable strawberry cultivar identification using inter simple sequence repeat (ISSR) amplification. Euphytica 129:69-79.

Blair, M.W., O. Panaud, and S.R. McCouch. 1999. Inter-simple sequence repeat (ISSR) amplification for analysis of microsatellite motiffrequency and fingerprinting in rice. Theor. Appl. Genet. 98:780-792.

Casasoli, M., C. Mattioni, M. Cherubini, and F. Villani. 2001. A genetic linkage map of European chestnut (Castanea sative Mill.) based on RAPD, ISSR and isozyme markers. Theor. Appl. Genet. 102:1190-1199.

Charters, Y.M., A. Robertson, M.J. Wilkinson, and G. Ramsey. 1996. PCR analysis of oilseed rape cultivars (Brassica napus L. ssp. oleifera) using 5 '-anchored simple sequence repeat (SSR) primers. Theor. Appl. Genet. 92:442-447.

Congiu, L., R. Cella, R. Rossi, and G. Bernacchia. 2000. The use of random amplified polymorphic DNA (RAPD) markers to identify strawberry varieties: A forensic application. Mol. Ecol. 9:229-232.

Denagi, C., L.J. Rowland, J.A. Saunders, S.C. Hokanson, E.L. Ogden, A. Golan-Goldhirsh, and G.J. Galletta. 2001. A comparison of genetic relationship measures in strawberry (Fragaria $\times$ ananassa Duch.) based on AFLPs, RAPDs, and pedigree data. Euphytica 117:1-12.

Evinson, R.J. 1998. The gardener's guide to growing clematis. Timber Press Inc., Portland, Ore.

Fair K. and C. Fair. 1990. Clematis: For color and versatility. The Crowood Press, Wiltshire.

Fang, D.Q. and M.L. Roose. 1997. Identification of closely related citrus cultivars with inter-simple sequence repeat markers. Theor. Appl. Genet. 95:408-417.

Fernández, M.E., A.M. Figueiras, and C. Benito. 2002. The use of ISSR and RAPD markers for detecting DNA polymorphism, genotype identification and genetic diversity among barley cultivars with known origin. Theor. Appl. Genet. 104:845-851.

Fisk, J. 1994. Clematis: The queen of climbers. Cassell Publ. Ltd., London.

Haymes, K.M. 1996. A DNA mini-prep method suitable for a plant breeding program. Plant Mol. Biol. Rpt. 14:280-284.

Jain,A., C. Apparanda, and P.L. Bhalla. 1999. Evaluation of genetic diversity and genome fingerprinting of Pandorea (Bignoniaceae) by RAPD and inter-SSR PCR. Genome 42:714-719.

Joshi, S.P., V.S. Gupta, R.K. Aggarwal, P.K. Ranjekar, and D.S. Brar. 2000. Genetic diversity and phylogenetic relationship as revealed by inter simple sequence repeat (ISSR) polymorphism in the genus Oryza. Theor. Appl. Genet. 100:1311-1320.

Keil, M. and A.R. Griffin. 1994. Use of random amplified polymorphic DNA (RAPD) markers in the discrimination and verification of genotypes in Eucalyptus. Theor. Appl. Genet. $89: 442-450$

Li, A. and S. Ge. 2001. Genetic variation and clonal diversity of Psammochloa villosa (Poaceae) detected by ISSR markers. Ann. Bot. 87:585-590.

Mattioni, C., M. Casasoli, M. Gonzalez, R. Ipinza, and F. Villani. 2002. Comparison of ISSR and RAPD markers to characterize three Chilean Nothofagus species. Theor. Appl. Genet. 104:1064-1070.

McGregor, C.E., C.A. Lambert, M.M. Greyling, J.H. Louw, and L. Warnich. 2000. A comparative assessment of DNA fingerprinting techniques (RAPD, ISSR, AFLP, and SSR) in tetraploid potato (Solanum tuberosum L.) germplasm. Euphytica 113:135-144.

Moreno, S., J.P. Martin, and J.M. Ortiz. 1998. Intersimple sequence repeat PCR for characterization of closely related grapevine germplasm. Euphytica 101:117-125.

Nagoaka, T. and Y. Ogihara. 1997. Applicability of inter-simple sequence repeat polymorphisms in wheat for use as DNA markers in comparison to RFLP and RAPD markers. Theor. Appl. Genet. 94:597-602.

Oraguzie, N.C., S.E. Gardiner, H.C.M. Basset, M. Stefanati, R.D. Ball, V.G.M. Bus, and A.G. White. 2001. Genetic diversity and relationships in Malus sp. germplasm collections as determined by randomly amplified polymorphic DNA. J. Amer. Soc. Hort. Sci. 126:318-328.

Pasakinskiene, I., C.M. Griffiths, A.J.E. Bettany, V. Paplauskiene, and M.W. Humphreys. 2000. Anchored simple-sequence repeats as primers to generate species-specific markers in Lolium and Festuca grasses. Theor. Appl. Genet. 100:384-390.

Patzak, J. 2001. Comparison of RAPD, STS, ISSR, and AFLP molecular methods for assessment of genetic diversity in hop (Humulus lupulus L.). Euphytica 121:9-18.

Prevost, A. and M.J. Wilkinson. 1999. Anew system of comparing PCR primers applied to ISSR fingerprinting of potato cultivars. Theor. Appl. Genet. 98:107-112.

Rajesh, P.N., V.J. Sant, V.S. Gupta, F.J. Muelbauer, and P.K. Ranjekar. 2002. Genetic relationships among annual and perennial wild species of Cicer using inter simple sequence repeat (ISSR) polymorphism. Euphytica 129:15-23.

Reddy, M.P., N. Sarla, and E.A. Siddiq. 2002. Inter simple sequence repeat (ISSR) polymorphism and its application in plant breeding. Euphytica 128:9-17.

Reed, S.M., Y. Joung, and M. Roh. 2002. Interspecific hybridization in Clethra. HortScience 
37:393-397.

Rohlf, F.J. 1998. NTSYS-pc: Numerical taxonomy and multivariate analysis system. Version 2.03f. Exeter Software, Setauket, N.Y.

Schnell, R.J., C.M. Ronning, and R.J. Knight, Jr. 1995. Identification of cultivars and validation of genetic relationships in Mangifera indica L. using RAPD markers. Theor. Appl. Genet. 90:269-274.

Snoeijer, W. 1991. Clematis index. Boskoop, The Netherlands

Starman, T.W., X. Duank, and S. Abbitt. 1999. Nucleic acid scanning techniques distinguish closely related cultivars of poinsettia. HortScience 34:1119-1122.
Tikunov, Y.M., L.I. Khrustaleva, and G.I. Karlov. 2003. Application of ISSR markers in the genus Lycopersicon. Euphytica 131:71-80.

Trigiano, R.N., M.C. Scott, and G. Caetano-Anollés. 1998. Genetic signatures from amplification profiles characterize DNA mutation in somatic and radiation-induced sports of chrysanthemum. J. Amer. Soc. Hort. Sci. 123:642-646.

USDA-NASS census. 1998. http://www.nass.usda. gov/census/census97/horticulture/table13.pdf.

Vijayan, K. and S.N. Chatterjee. 2003. ISSR profiling of Indian cultivars of mulberry (Morus spp.) and its relevance to breeding programs. Euphytica 131:53-63.

Virchow, D. 2003. Efficient conservation of crop diversity. Springer-Verlag, New York.

Yang, W., A.C. de Oliveira, I. Godwin, K. Schwertz, and J.L. Bennetzen. 1996. Comparison of DNA marker technologies in characterizing plant genome diversity: Variability in Chinese sorghums. Crop Sci. 36:1669-1676.

Yap, I.V. and R.J. Nelson. 1996. WinBoot: A program for performing bootstrap analysis of binary data to determine the confidence limits of UPGMA-based dendrograms. Intl. Rice Res. Inst., Manilla, Philippines.

Zietkiewicz,Z.A.,A. Rafalski, and D. Labuda. 1994. Genome fingerprinting by simple sequence repeat (SSR)-anchored polymerase chain reaction amplification. Genomics 20:176-183. 